\title{
Pancreatic Polypeptide Measurement
}

National Cancer Institute

\section{Source}

National Cancer Institute. Pancreatic Polypeptide Measurement. NCI Thesaurus. Code C80201.

The determination of the amount of pancreatic polypeptide present in a sample. 